\title{
S5ynthesis
}

International Scientific Conference of IT and Business-Related Research

\section{ULOGA IGRANOG FILMA U PROMOCIJI TURISTIČKE DESTINACIJE}

\section{FEATURE FILM AS A FACTOR AFFECTING TOURISM DESTINATION PROMOTION}

\author{
Branislav Tanasić \\ Ministarstvo finansija Republike Srbije
}

\begin{abstract}
Apstrakt:
Opšte je poznato da knjiga ili umetnička slika mogu podstaknuti pojedinca da mašta o putovanju na neko novo i egzotično mesto. Isto tako film se može smatrati važnim faktorom koji podstiče i promoviše razvoj turizma u savremenom dobu, i koji kroz svoje pokretne slike može da navede gledaoca da poželi da otputuje na određenu destinaciju (planinu ili more) u pokušaju da oživi avanture svojih junaka sa filmskog platna. Uticaj igranog filma može biti toliko snažan da navede pojedinca da se fizički transformiše u svog omiljenog junaka. Efekti pokretnih slika takođe mogu biti čudesni. Turistički statistički podaci ukazuju na značajan porast broja dolazaka na destinacije na kojima su snimana velika filmska ostvarenja. Autor će pokušati da otkrije šta se krije iza magije zamračene bioskopske sale koja budi avanturistički duh u gledaocu i pokreće ga da poseti i istraži destinacije na kojima su snimljeni njegovi omiljeni filmovi.
\end{abstract}

\section{Ključne reči:}

reklama, putovanje, bioskop, film, destinacija.

\section{UVOD}

Kada se osamdesetih godina prošlog veka, glumac Tom Kruz pojavio u filmu Rizičan posao noseći Ray-Ban naočari za sunce, prodaja ovog artikla je skočila za 50\%. Tri godine kasnije, nonšalantno izlazi iz borbenog aviona u filmu Top Gun, naravno noseći ove već legendarne retro-naočari, i prodaja skače za dodatnih 40\% (Lindstrom, 2010).

Obeležavajući 50 godina slavnog filmskog junaka agenta 007, franšiza Visit Britain lansirala je 2012. godine najveću filmsku turističku kampanju ikada, fokusirana na Skyfall, dvadesettreću po redu James Bond avanturu. Modiano o ovom propagandnom poduhvatu kaže: „Prateći avanture i uzbudjenja agenta 007, Visit Britain's promocija uključuje svoju najveću filmsku turističku kampanju koja će biti viđena u bioskopima ključnih tržišta, kao što su Australija, Brazil, Nemačka i SAD. Brojni bilbordi nose natpise Bond is Great Britain, koji takođe podsećaju ljude da nema boljeg časa da posete Britaniju i istražite dom svetski najpopularnijeg tajnog agenta. U proseku 120 miliona ljudi širom sveta, videće film u prve tri nedelje prikazivanja. Istraživanja pokazuju da filmske lokacije mogu biti glavni pokretač prekomorskih turista. Istraživanje posetite Britaniju pokazuje da gotovo polovina potencijalnih posetilaca Britanije želi da obiđe mesta koja su videli na filmu ili na TV." (Modiano, 2012)

$\mathrm{U}$ filmu se retko koriste originalne lokacije, ali posetioci osećaju potrebu da posete destinaciju koja je deo filmske priče.

\section{Abstract:}

It is well-known that a book or an art painting can spur one's imagination about travelling to new and exotic destinations. The movie is also considered an important factor in the modern world influencing destination image, as its motion pictures encourage the viewers to dream of visiting the filming destinations and recreating images of their favourite characters. Some may be so enchanted as to dress in the same manner as the characters from the big screen. The effects of motion images can be miraculous. Namely, tourism statistics show a significant increase in the number of arrivals to the filming locations. The author shall attempt to discover the magic of slightly dimmed cinemas that awakens the viewer's curiosity to explore and motivates them to dream of traveling to some filming location.

\section{Key words:}

advertising, traveling, cinema, film, destination.

U eseju Filmski turizam naveden je primer: Film Hraboro srce je značajno podigao turističku posetu Škotskoj, iako je uglavnom sniman u Irskoj! Škoti su podigli spomenik sa likom Mela Gibsona, koji danas predstavlja turističku atrakciju.

Zatim iznosi vrlo indikativan primer iz Bostona: Tom Kershaw, vlasnik hotela Bull and Finch, kaže da je njegov bar korišćen za snimanje brojnih epizoda serije Cheers. Direktna ekonomska korist koju je vlasnik realizovao, uključuje oko 500.000 posetilaca paba godišnje, uz promet hrane i piva preko 6 miliona dolara (Tunstill, 2010).

Šta to pokreće pola miliona ljudi da dođu i popiju pivo baš u ovom pabu? Dramski zaplet u seriji začet na tom mestu, glavni likovi, atraktivnost same lokacije ili vešta kombinacija režisera ovih elemenata i glamurozna produkcija serije. Pokušaćemo da malo zavirimo iza objektiva kamere i bacimo novo svetlo na ovaj fenomen.

\subsection{FILMSKE LOKACIJE KAO TURISTIČKE DESTINACIJE}

Za kulturni turizam možemo reći da je edukativna forma kroz koji ljudi mogu da nauče više o drugačijem stilu života, kroz način na koji neka država prezentuje posetiocima svoju hranu, muziku, gostoljubivost, arhitekturu, domaću radinost i zabavu, odnosno kulturne faktore. Kao deo umetničkog izraza, kulture i lokalne tradicije, a pre svega kao deo industrije zabave, film koji pokreće turizam, može se nazvati delom kulturne turističke baštine (McKercher, 2002). Film koji pokreće turizam je forma 
turizma koja se može podvesti pod krovni termin kulturnog turizma, koji podstiče razvoj industrije zabave i međunarodna putovanja (Hudson \& Richie, 2006). Kao deo kulturnog turizma, to je potraga za spomenicima i istorijskim mestima. Takođe „filmski turisti“"pokušavaju da pronađu one vizuelne doživljaje, takozvane markere, koji ih živo podsećaju na scene viđene u filmu (Roesh, 2009). Često se dešava da neki objekt ili mesto predstavljeno u filmu bude prepoznato kao destinacija gde je gledalac već boravio, što budi određene emocije i može da osveži želju da ponovi putovanje. Film Praznik u Rimu, snimljen 1953. godine, sa Odri Hepbern i Gregori Pekom u glavnim ulogama, i naravno grad Rim, odličan je primer. Obilje scena u eksterijeru, sa prepoznatljivim lokacijama večitog grada, rezultirali su povećan broj turista koji su želeli da uživo obiđu lokacije prepoznate iz, sada možemo reći, kultnog filma.

Nakon snimanja filma Boni i Klajd, dovitljivi vlasnik jedne turističke agencije crvenim mastilom je preko štampanog teksta brošure ispisao: Posetite mesto pogibije Boni i Klajda! Više nije bilo važno da li je to stvarno mesto istorijskog događaja, filmska ekipa je tu snimala, i to je dalo sertifikat lokaciji - običnoj poljani pored puta, gde nije postojalo ništa drugo osim divljeg rastinja. Posetioci i nemaju neka velika očekivanja, dovoljno je da su na lokaciji velikog događaja (MacCannell, 1976).

Kao što smo već rekli, čuveni film Hrabro srce sa Melom Gibsonom u glavnoj ulozi, najvećim delom snimljen je u Irskoj, a nakon svetske premijere, ljudi su masovno pohrlili u Škotsku! Očigledno je snaga istorijske ličnosti Vilijama Valasa odnela prevagu. Film je mogao biti snimljen bilo gde, ali Valas je Škot i ljudi su masovno krenuli u obilazak postojbine hrabrog srca - Škotsku. Još jedan filmski hit, blokbaster, dao je zamaha škotskom turizmu. Tajna Da Vinčijevog koda, mistični filmski zaplet o templarima, već sama po sebi dovoljno intrigantna tema, sa ključem za razrešenje tajne u Roslin kapeli (Rosllyn Chapel) nedaleko od Edinbuga. Vešto isprepletana priča, mešavina mitova, istorijskih činjenica i filmskog zapleta, večita tema - potraga za Svetim gralom koji je, po filmskoj varijanti, sklonjen u srednjovekovnu templarsku kapelu, rezultirala je pravom bujicom turista u Edinburgu, kao i u samu kapelu lociranu u blizini škotske prestonice.

Brojni su primeri izuzetnog porasta broja turista, kada nakon filmske premijere, lokacije na kojima su snimani upečatljivi kadrovi, postaju atraktivne destinacije (tabela 1).

\begin{tabular}{|c|c|c|}
\hline Film & Lokacija & Posećenost \\
\hline Hrabro srce & Škotska & broj turista je veći za 300\% \\
\hline Ples sa vukovima & Fort Hayes, Kanzas & porast posete $25 \%$ \\
\hline Polja snova & Ajova & beleži porast od $35 \%$ \\
\hline Gospodar prstenova & Novi Zeland & $\begin{array}{l}\text { svake godine broj posetilaca iz UK u } \\
\text { porastu je } 10 \%\end{array}$ \\
\hline Hari Poter & više lokacija u UK & beleži porast od $50 \%$ \\
\hline Krokodil Dandi & Australija & beleži porast američkih turista za $20,5 \%$ \\
\hline Plaža & Tajland & $\begin{array}{l}\text { beleži porast } 22 \% \text { mlade populacije u } \\
2000 \text {. god. }\end{array}$ \\
\hline Nemoguća misija 2 & Nacionalni park, Sidnej & porast posete $200 \%$ u 2000 . god. \\
\hline Četiri venčanja i sahrana & The Crown Hotel, UK & $\begin{array}{l}\text { potpuno popunjen hotel najmanje tri } \\
\text { godine. }\end{array}$ \\
\hline Spasavanje redova Rajana & Normandija, Francuska & porast posete američkih turista za $40 \%$. \\
\hline Gordost i predrasude & Lyme Park, UK & porast posete $150 \%$ \\
\hline Troja & Čanakale, Turska & povećanje broja turista $73 \%$. \\
\hline $\begin{array}{l}\text { Mandolina kapetana } \\
\text { Korelija }\end{array}$ & Kefalonija, Grčka & beleži se povećanje broja turista od $50 \%$ \\
\hline
\end{tabular}

Tabela 1. Uticaj filma na povećanje broja turista.

Izvor: Hudson \& Ritchie (2006)
Već na prvi pogled je jasno koliko značajan uticaj na neke destinacije mogu imati filmske projekcije, kroz povećanje broja turističkih poseta. Atraktivnost filmskih lokacija za turiste, kao novog tipa turističke destinacije, skreće pažnju ne samo turističkih marketara, već i mnogih istraživača koji se bave korelacijom film - turizam, pa postoje brojne studije na ovu temu. Tako Woodward govori o mogućnostima DMO (Destination Marketing Organizations) odnosno, aktivnostima koje marketari neke destinacije mogu preduzeti pre snimanja filma, i generisanje koristi u toku i nakon projekcija filmskog ostvarenja. „Uprkos činjenici da DMO često ne može uticati na izbor gde će film biti produciran, oni mogu biti proaktivni promoteri svoje lokacije filmskim producentima. Većina destinacija ima fokus na kratkoročnu korist od filmske produkcije, ali neke su aktivne u podršci producentima da snimaju filmove u njihovom regionu, u cilju dugoročne koristi i uticaja na turizam. Dobar primer za DMO su Britanija, SAD i Singapur. Visit Britain za ciljnu grupu ima indijske filmske producente, za koje veruje da ih može ubediti da koriste britanske lokacije za snimanje indijskih filmova (Bollywood films) koji će generisati ekonomsku korist za britansku turističku industriju." (Woodward, 2000)

Neke destinacije angažuju profesionalne agencije za odnose sa javnošću, kako bi plasirale svoj region na film. Kanada i Bahami identifikovali su filmski turizam kao dobru marketinšku priliku i angažovali su jednu od najvećih firmi za odnose sa javnošću (Weber Shandwick), kako bi njihova destinacija bila zastupljena na televiziji i filmu (Shandwick, 2005).

Švajcarska turistička zajednica je odlučila da će kao stimulans za povećanje broja turista iz Indije, platiti sve troškove za direktore filmske industrije u Indiji (Bollywood), ukoliko se snimanje filmova bude odvijalo u Švajcarskoj (Mehta, 2004).

Tokom snimanja Gospodara prstenova, medijski izveštaji su redovno napominjali da se film snima na Novom Zelandu, obezbeđujući ranu povezanost filma i lokacije. Filmske zvezde su takođe pomogle u promovisanju Velingtona, glavnog grada Novog Zelanda (Woodward, 2000).

Gromoglasna propaganda takođe se može dovesti u vezu sa aktivnostima glumaca tokom trajanja snimanja na datoj lokaciji. Prilikom ekranizacije knjige Mandolina kapetana Koreliija na velikom filmskom platnu, ogromnu pažnju privuklo je dvoje protagonista (Nikolas Kejdž i Penelope Kruz). Film je doživeo svoju premijeru u bioskopima širom sveta i tako doprineo sve većoj popularnosti Kefalonije kao destinacije na kojoj je sniman istoimeni film. Pomenuti par je navodno imao ljubavnu aferu, što je dodatno uticalo na popularnost filma i Kefalonije kao turističke destinacije (Ward, 2001).

Za vreme snimanja i nakon realizacije filma, medijska pažnja može biti privučena na filmsku lokaciju. Na primer, uprava turizma Tajlanda (TAT), uporno je reklamirala svoje turističke atrakcije tokom snimanja filma Plaža. Marketinška kampanje uključuje i neprestane zajedničke aktivnosti sa $20^{\text {th }}$ Century Fox, u cilju kapitalizacije očekivane buduće popularnosti Thai plaža koje će biti viđene na filmu (Grihault, 2003).

Turistička komisija Australije godinama koristi usluge glumca Pola Hogana, za promociju svog turizma prateći svetski uspeh hit filma Krokodil Dandi (Hudson \& Ritchie, 2006). 
Promocija destinacije za vreme prikazivanja filma je drugi način za privlačenje pažnje. Škotska turistička zajednica, distribuirala je reklamne dopisnice, sa plaćenom poštarinom, svim bioskopima u kojima se prikazivao film Hrabro srce, pozivajući gledaoce da pišu i šalju informacije o domovini Hrabrog srca (Grihault, 2003).

U periodu koji filmske projekcije većina DMO biva angažovana u pokušaju da iskoristi popularnost i uticaj filma na gledaoce. U ovoj fazi izazov za DMO je da pažnju auditorijuma sa filma transformišu u interes za putovanje. Marketinške mogućnosti se generišu kroz više vidova distribucije filma (bioskop, video, DVD, televizija). Tradicionalno ovaj ciklus traje par godina, ali može biti znatno kraći, ukoliko je prodaja DVD dobra. (Buckley, 2004)

Veoma dobra i interesantna je studija pod naslovom „Filmski turizam" (Beeton, 2005), objašnjava fenomen filma i uticaja na turiste da se odluče za putovanje, ali otvara i brojna pitanja. Istraživanje može da se sprovede na primenjen ili teoretski način. Primenjeno istraživanje traži odgovore na specifična pitanja kao što je važnost filmske lokacije (bilo da je stvarna ili fiktivna - studijska), i njen uticaj na male zajednice.

Teoretski, mogu se postaviti brojna pitanja od kojih izdvajamo:

- Šta zaista čini film pokretačem turizma, koji su to elementi koji film kreiraju kao pokretača turizma i kako su kombinovani?

- Kada je film primarni, a kada sekundarni motivator i zašto?

- Koji je to psihološki pokretač u filmu koji motiviše želju za putovanjem?

- Koji je efekt drugih tipova filma na turiste, kao dokumentarni film iz realnog života ili naučno fantastični film?

- Kako je najlakše prezentovati neku lokaciju?

- Da li kulturne razlike u filmu, pokreću turističko tržište?

- Kako mogu pomoći studije istorije filma i turizma u boljem razumevanju razvoja turizma i uticaja filma na turizam? (Beeton, 2005)

\section{ZAKLJUČAK}

Verujemo da smo na neka pitanja dali makar delimičan odgovor, dok su neki izneti problemi predmet za podrobnije istraživanje i analize. Dodali bismo da izuzetno delotvorna marketinška ponuda može biti organizovanje turističkih tura, obilazak filmskih lokacija - stvarnih (on-site) ili fiktivnih - studijskih (off site). Izrađuju se turističke mape, kao pomoć turistima u pra- ćenju lokacija korišćenih tokom snimanja. Zaista su bezbrojni načini da se animiraju turisti da dođu na neku filmsku lokaciju, ili kada su već tu da im se veže pažnja za raznovrsne sadržaje: od ponude delova odeće, korišćenih rekvizita tokom snimanja, ne retko aukcijske prodaje automobila filmskih zvezda - koji često dostižu vrtoglave dolarske iznose, do ponude šminke i sličnih sitnica za koje se pouzdano tvrdi da su autentične.

\section{LITERATURA}

Beeton, S. (2005). Film-induced tourism. Clevedon: Channel View Publications.

Buckley K. (2004). DVD Sets Rules for Hollywood, Financial Times, January 23, str. 12

Grihault, N. (2003). Film Tourism: The Global Picture. Travel and Tourism Analyst, 5, 1- 22. Dostupno na: http://aboutourism.wordpress.com/2012/10/09/film- tourism-destination-marketing/

Hudson, S. (2006). Promoting Destinations via Film Tourism: An Empirical Identification of Supporting Marketing Initiatives. Journal of Travel Research. DOI: $10.1177 / 0047287506286720$

Lindstrom, M. (2010). Kupologija. Beograd: Laguna.

MacCannell, D. (1976). The tourist: A new theory of the leisure class. New York: Schocken Books.

McKercher, B., \& Du Cros, H. (2002). Cultural tourism: The partnership between tourism and cultural heritage management. New York: Haworth Hospitality Press.

Mehta, I. (2004). Welcome to Bollywood. National Geographic, 207(2), 52-69.

Modiano, D. (2012). James Bond on Visit's Britain Service. Dostupno na: http://www.visitbritain.org/aboutus/recentactivity/bondisgreatbritain.aspx

Roesch, S. (2009). The experiences of film location tourists. Bristol: Channel View Publications.

Tunstill, J. (2010). Film Induced Tourism. Dostupno na www. reelstreets.com/index.php/articles/john-tunstill/1-filminduced-tourism

Ward, I. (2001). Island Life trough a Lens Boosts Bookings. Travel Trade Gazette, p. 40

Weber Shandwick. (2005). Weber Shandwick Embarks on 'Destination: Entertainment Marketing to Put the Travel and Tourism Industry in the Spotlight, http://www.webershandwick.com

Woodward, I. (2000). Why Should the UK's Tourism Industry be interested in Bollywood films? Insight, 12: A 23-26. 